\section{Effectiveness of preoperative ultrasound-guided charcoal tattooing for localization of metastatic melanoma}

\author{
Ji Hyun Lee', Hyun Su Kim', Young Cheol Yoon', Min Je Kim', Min Jae Cha², \\ Jung-Han $\mathrm{Kim}^{3}$
}

\author{
'Department of Radiology, Samsung Medical Center, Sungkyunkwan University School of \\ Medicine, Seoul; ${ }^{2}$ Department of Radiology, Chung-Ang University Hospital, Chung-Ang \\ University College of Medicine, Seoul; ${ }^{3}$ Department of Surgery, Samsung Medical Center, \\ Sungkyunkwan University School of Medicine, Seoul, Korea
}

Purpose: Excision of metastatic lesions is an important treatment strategy in patients with malignant melanoma, both at the initial diagnosis and upon recurrence. Since nonpalpable lesions cannot be easily visualized in the surgical field, we evaluated the effectiveness of ultrasound (US)-guided tattooing using a charcoal suspension for the localization of nonpalpable metastatic lesions of malignant melanoma.

Methods: Between November 2009 and June 2019, we retrospectively reviewed 65 nonpalpable lesions in 29 patients with malignant melanoma who underwent preoperative US-guided tattooing using a charcoal suspension for histologically confirmed or suspected metastases. The characteristics of the tattooed lesions were analyzed. The effectiveness of the procedure was evaluated based on the detection rate in the surgical field and the presence or absence of residua on postoperative follow-up US. Procedure-related complications were also analyzed.

Results: Of 65 lesions, 33 (50.8\%) were histologically confirmed as metastases before the tattooing procedure, while the other 32 were suspected of being metastases based on imaging studies. The mean lesion size was $9.8 \mathrm{~mm}$ (range, 1.3 to $24.4 \mathrm{~mm}$ ). The final pathology revealed metastases in 59 lesions (90.8\%), including lymph node $(n=51)$, muscle $(n=5)$, and in-transit $(n=3)$ metastases. Sixty-one lesions (93.8\%) were successfully detected intraoperatively and removed without residua on follow-up US. Four residual lesions were removed after repeated localization ( $n=2)$ or by intraoperative US $(n=2)$. No relevant complications were noted.

Conclusion: Preoperative US-guided tattooing localization can safely and effectively delineate nonpalpable metastatic melanoma lesions to aid in successful surgical excision.

Keywords: Ultrasonography; Interventional ultrasonography; Melanoma; Neoplasm metastasis; Tattooing

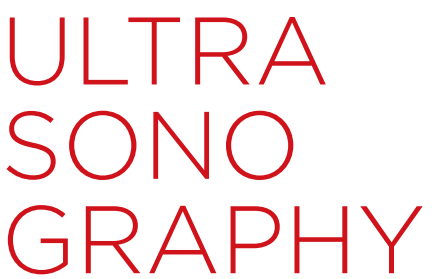

ORIGINAL ARTICLE

https://doi.org/10.14366/usg.20013 pISSN: 2288-5919 - elSSN: 2288-5943

Ultrasonography 2020;39:376-383

Received: January 28, 2020

Revised: March 17, 2020

Accepted: March 18, 2020

Correspondence to:

Hyun Su Kim, MD, Department of Radiology, Samsung Medical Center, Sungkyunkwan University School of Medicine, 81 Irwon-ro, Gangnam-gu, Seoul 06351, Korea

Tel. +82-2-3410-0557

Fax. +82-2-3410-0084

E-mail: calmuri@naver.com

This is an Open Access article distributed under the terms of the Creative Commons Attribution NonCommercial License (http://creativecommons.org/ licenses/(by-nc/4.0/) which permits unrestricted noncommercial use, distribution, and reproduction in any medium, provided the original work is properly cited.

Copyright @ 2020 Korean Society of Ultrasound in Medicine (KSUM)

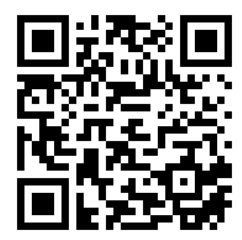

How to cite this article:

Lee JH, Kim HS, Yoon YC, Kim MJ, Cha MJ, Kim $\mathrm{JH}$. Effectiveness of preoperative ultrasoundguided charcoal tattooing for localization of metastatic melanoma. Ultrasonography. 2020 Oct;39(4):376-383. 


\section{Introduction}

Lymph node involvement is of the utmost importance in the management of patients with melanoma, as it affects their prognosis and the choice of an appropriate surgical procedure [13]. Since $66 \%$ of recurrent melanomas develop in the regional lymph node basin, regional lymph nodes are an important target of surveillance even after surgery [4]. In-transit metastasis, which represents non-nodal cutaneous or subcutaneous disease between the primary site and the regional lymph node basin, and distant metastasis are also important prognostic factors that influence treatment strategies [5-9]. Ultrasonography (US) has proven to be an excellent imaging modality for the initial and follow-up evaluation of metastatic lesions and provides guidance for histologic confirmation procedures in patients with melanoma $[2,10-12]$. Numerous studies have reported that US is superior to palpation in the detection of metastatic lesions $[10,11,13]$. These results suggest that US can aid in the detection and management of metastatic lesions that are nonpalpable, possibly due to their small size, deep location, or overlying fibrotic scar tissue related to previous surgery.

In patients with nodal recurrence after previous excision, excision of the recurrent lesion is recommended according to clinical practice guidelines [14]. Moreover, in patients with clinically positive lymph node metastasis identified during the initial workup, complete lymph node excision, including the identified lesion, in addition to excision of the primary tumor is recommended as the primary treatment [14]. Additionally, definitive surgical resection has been proven to be effective for in-transit or distant metastases, although they are considered to be indicators of advanced disease $[8,9]$. Thus, it is desirable for surgeons to easily recognize histologically confirmed or suspected metastases that are not palpable during surgery to achieve accurate removal of these lesions. Preoperative localization can be a useful option for such cases. A number of techniques for the localization of nonpalpable metastatic melanoma have been proposed, such as insertion of a wire or radioactive material within the targeted lesion under imaging guidance [15-19]. However, those procedures were reported in an extremely small number of cases and have not been established as standard treatment.

US-guided tattooing using a charcoal suspension has been widely performed for the preoperative localization of nonpalpable metastases in thyroid and breast cancer [20-25]. It has been accepted as a safe and effective procedure for indicating the location of the targeted lesions before surgical excision. To our best knowledge, no data have been reported on US-guided charcoal tattooing for the preoperative localization of nonpalpable metastatic melanoma. We hypothesized that tattooing metastatic melanoma lesions would allow them to be reliably identified intraoperatively and aid in their excision.

In this study, we evaluated the effectiveness of US-guided tattooing using a charcoal suspension for the preoperative localization of nonpalpable metastatic melanoma, mainly focusing on its visibility during surgery and the successful removal of the lesions thereafter.

\section{Materials and Methods}

\section{Patients}

Our institutional review board approved this retrospective study, and the requirement for informed patient consent was waived. From November 2009 to June 2019, we identified 29 consecutive patients with malignant melanoma (16 men and 13 women; median age, 60 years; range, 25 to 84 years) who underwent preoperative USguided charcoal tattooing of 65 nonpalpable lesions. All patients included in the study met the following criteria for US-guided charcoal tattooing: (1) history of histologically confirmed primary malignant melanoma; (2) metastatic lesions that were either histologically confirmed or suspected based on an imaging study performed prior to US-guided charcoal tattooing; and (3) follow-up US performed within 6 months postoperatively.

\section{US-Guided Charcoal Tattooing Procedure}

A sterilized $3 \% \mathrm{w} / \mathrm{w}$ aqueous suspension of activated charcoal granules (Duksan Pure Chemicals, Ansan, Korea) was prepared at the Division of Pharmaceutical Services of our institution. Activated charcoal $(0.3 \mathrm{~g})$ was added to $10 \mathrm{~mL}$ of normal saline, and the suspension was filtered through a blue filter with a pore size of 0.2 $\mu \mathrm{m}$. The preparation was distributed in $10 \mathrm{~mL}$ bottles and sterilized in $120^{\circ} \mathrm{C}$ steam for 20 minutes $[20,21]$.

Tattooing procedures were performed by either musculoskeletal staff radiologists or musculoskeletal radiology fellows. After identifying the lesions by US, $1 \%$ lidocaine was injected into the skin selected as the entry site for local anesthesia. Then, $<1 \mathrm{~mL}$ of the charcoal suspension was aspirated using a $5-\mathrm{mL}$ syringe and an 18-G needle to prevent blockage by precipitation. A $12-5$ or $15-7$ $\mathrm{MHz}$ linear transducer (iU22, Philips Medical Systems, Bothell, WA, USA) was used for guidance and image acquisition depending on the examiner's preference. With the US transducer placed parallel to the needle to allow real-time guidance, a needle was advanced into the lesion until its tip was located at the center. The charcoal suspension was injected slowly as the needle was withdrawn to the point of skin entry (Fig. 1). Skin marking was done at the entry site to enable the surgeons to identify the site easily. 


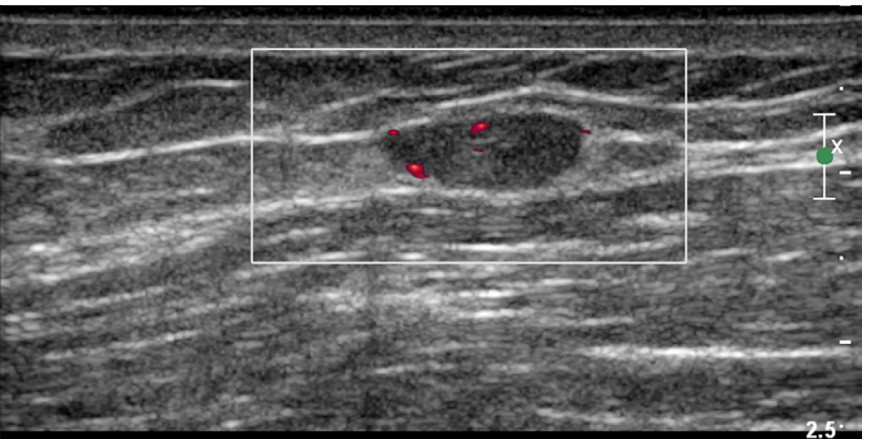

A

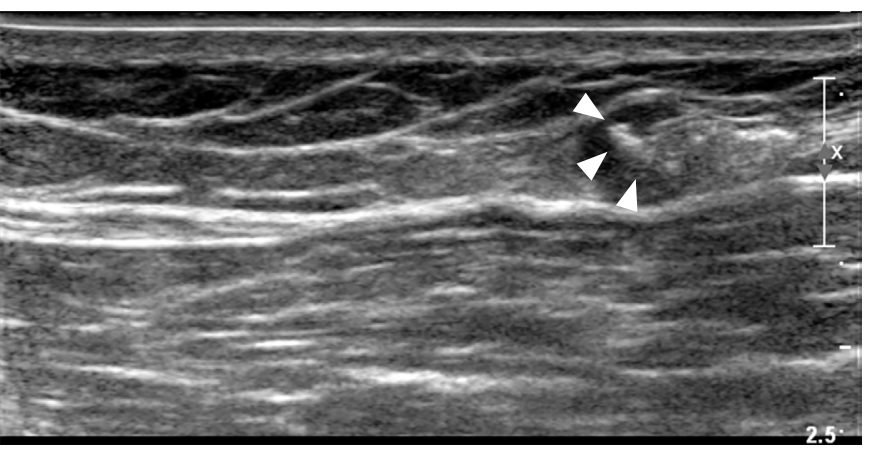

C

\section{Assessment of the Effectiveness of US-Guided Charcoal Tattooing Localization}

The characteristics of the patients and tattooed lesions were determined by a retrospective review of patients' electronic medical records. The effectiveness of this procedure was evaluated in terms of the percentage of intraoperatively detected and removed lesions without residua on follow-up US of all tattooed lesions. US images were obtained during follow-up performed within 6 months postoperatively, and surgical and pathological reports were retrospectively reviewed. Moreover, the occurrence of procedurerelated complications was analyzed.

\section{Results}

Table 1 summarizes the baseline characteristics of the 29 patients who underwent preoperative US-guided tattooing localization for histologically confirmed or suspected metastatic malignant melanoma. The lower extremity was the most common location of the primary malignant melanoma ( 22 of $29,75.9 \%$ ), followed by the upper extremity, trunk, and anus. A majority of the patients (22 of $29,75.9 \%$ ) underwent US-guided charcoal tattooing for recurrent disease.

The histologic characteristics of the 65 tattooed lesions in the 39 US-guided tattooing procedures are shown in Table 2. Most lesions

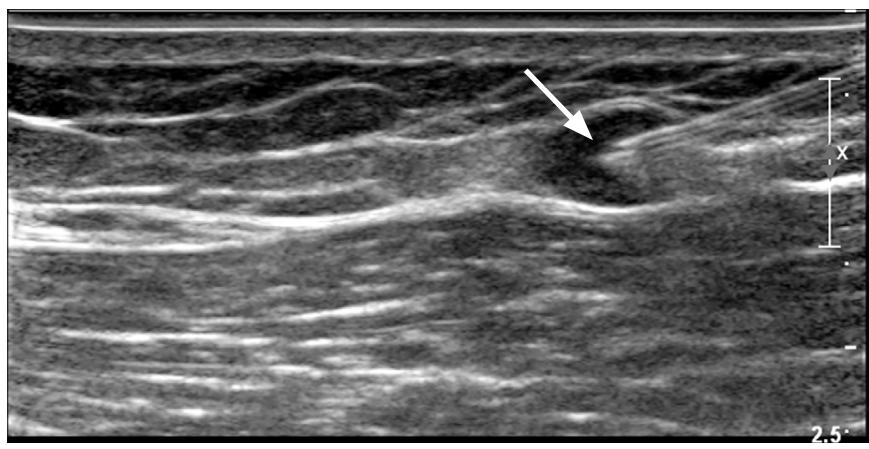

Fig. 1. Ultrasonography of the preoperative tattooing procedure performed for a metastatic lymph node in the left thigh of a 56-year-old man.

A. The metastatic lymph node shows increased vascularity on a power Doppler image. B. A needle tip (arrow) was inserted within the metastatic lymph node. C. The injected charcoal material (arrowheads) within the lymph node was demonstrated as irregular echogenicities.

Table 1. Baseline characteristics of 29 patients who underwent preoperative ultrasound-guided tattooing localization

\begin{tabular}{lc}
\multicolumn{1}{c}{ Characteristic } & Value \\
\hline Sex (male:female) & $16: 13$ \\
Age (yr), median (range) & $60(25-84)$ \\
Site of primary tumor, $\mathrm{n}(\%)$ & \\
Lower extremity & $22(75.9)$ \\
Upper extremity & $3(10.3)$ \\
Trunk & $2(6.9)$ \\
Anus & $2(6.9)$ \\
Initial presentation or recurrent tumor, $\mathrm{n}(\%)$ & \\
Initial presentation & $7(24.1)^{\mathrm{a})}$ \\
Recurrent tumor & $22(75.9)^{\mathrm{b})}$ \\
\hline
\end{tabular}

a) 13 lesions in 7 procedures. ${ }^{\text {b) }} 52$ lesions in 32 procedures.

(61 of $65,93.8 \%$ ) were initially detected by US performed prior to the tattooing procedure, while the other four lesions were initially detected by ${ }^{18} \mathrm{~F}$-fluorodeoxyglucose-positron emission tomography/ computed tomography $\left({ }^{18} \mathrm{~F}-\mathrm{FDG} \mathrm{PET} / \mathrm{CT}, \mathrm{n}=3\right)$ and contrastenhanced computed tomography $(C T, n=1)$. Moreover, 38 lesions (58.5\%) were histologically evaluated prior to tattooing, by either US-guided fine needle aspiration $(n=23)$ or core needle biopsy $(n=15)$, which revealed metastases in 18 and 15 cases, respectively. 
Table 2. Histological characteristics of the 65 tattooed lesions in 39 procedures

\begin{tabular}{lc}
\multicolumn{1}{c}{ Characteristic } & No. (\%) \\
\hline Imaging modality of detection prior to tattooing & $61(93.8)$ \\
Ultrasound & $3(4.6)$ \\
${ }^{18}$ F-FDG PET/CT & $1(1.5)$ \\
Contrast-enhanced CT & \\
Ultrasound-guided histologic confirmation prior \\
to tattooing localization \\
Aspiration \\
$\quad$ Metastasis \\
Inconclusive histology & $18(35.4)$ \\
Inadequate tissue specimen & $2(3.1)^{\mathrm{a})}$ \\
Biopsy & $3(4.6)^{\mathrm{b})}$ \\
Metastasis & $15(23.1)$ \\
None & $15(23.1)$ \\
Final pathology of tattooed lesion & $27(41.5)$ \\
Metastasis & \\
Benign reactive lymph node & $59(90.8)^{\mathrm{c})}$ \\
Traumatic neuroma & $5(7.7)$ \\
\hline
\end{tabular}

${ }^{18} \mathrm{~F}-\mathrm{FDG} \mathrm{PET} / \mathrm{CT},{ }^{18} \mathrm{~F}$-fluorodeoxyglucose-positron emission tomography/computed tomography; $\mathrm{CT}$, computed tomography.

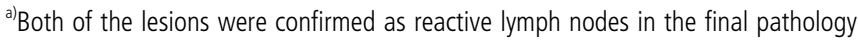
report. ${ }^{b}$ Two of the lesions were confirmed to be metastases and the third lesion was confirmed to be a reactive lymph node in the final pathology report. ${ }^{\text {c) }}$ ifty-one were metastatic lymph nodes, five were muscle metastases, and three were in-transit metastases.

In some cases, tattooing was requested by a clinician for lesions with inconclusive histology $(n=2)$ or inadequate tissue specimen quality $(n=3)$. Twenty-seven ( $41.5 \%)$ lesions that required tattooing did not undergo histological confirmation, but metastases were suspected based on the following imaging studies: ${ }^{18} \mathrm{~F}$-FDG PET/CT alone $(n=9)$; US alone $(n=12)$; both PET/CT and US $(n=5)$; and CT $(n=1)$. Six of the lesions were benign, consisting of reactive lymph nodes $(n=5)$ and traumatic neuroma $(n=1)$ according to the final pathology report. Otherwise, the final pathology reports revealed that all lesions were metastases (59 of $65,90.8 \%$ ), including metastatic lymph nodes $(n=51)$, muscle metastasis $(n=5)$, and intransit metastasis $(n=3)$.

The mean size of the lesions measured by US during the procedure was $9.8 \mathrm{~mm}$ (range, 1.3 to $24.4 \mathrm{~mm}$ ), and the majority of them were located in the inguinal area and thigh (Table 3). There were two lesions with a diameter $>2 \mathrm{~cm}$ that were not palpable due to their deep location within the muscle layer and overlying postoperative fibrosis with seroma. Most lesions were located in the subcutaneous fat layer ( 60 of $65,92.3 \%$ ). Fourteen lesions were in
Table 3. Clinical and ultrasound-related characteristics of the 65 tattooed lesions in 39 procedures

\begin{tabular}{lc}
\hline \multicolumn{1}{c}{ Characteristic } & Value \\
\hline Size (mm) & $9.8 \pm 5.6(1.3-24.4)$ \\
Anatomic location & \\
Area & \\
Inguinal & $30(46.2)$ \\
Thigh & $21(32.3)$ \\
Calf & $8(12.3)$ \\
Popliteal & $3(4.6)$ \\
Axilla & $2(3.1)$ \\
$\quad$ Upper back & $1(1.5)$ \\
Depth & \\
Subcutaneous fat layer & $60(92.3)$ \\
Muscle layer & $5(7.7)$ \\
Lesion in close proximity with major structure & $14(21.5)$ \\
Femoral vessel & $11(16.9)$ \\
Spermatic cord & $2(3.1)$ \\
Popliteal vessel & $1(1.5)$ \\
No. of tattooed lesions per procedure & $1.7 \pm 1.1(1-6)$ \\
No. of tattooing procedures per patient & $1.5 \pm 1.1(1-4)$ \\
Mean time of tattooing procedure (min) & $13.0 \pm 6.1(4-27)$ \\
Mean time between tattooing procedure and & $5.4(1-24)$ \\
operation (hr) & \\
Ultrasound probe used for tattooing localization & $32(82.1)^{\mathrm{a})}$ \\
12-5 MHz linear transducer & $7(17.9)^{\mathrm{a})}$ \\
15-7 MHz linear transducer & \\
\hline & \\
\hline
\end{tabular}

Values are presented as mean \pm standard deviation (range) or number (\%).

${ }^{a}$ Data are presented as numbers of procedures.

close proximity to a major vessel or spermatic cord. The mean time required for the procedure was 13 minutes (range, 4 to 27 minutes), and the mean time interval between tattooing and surgery was 5.4 hours (range, 1 to 24 hours).

During surgery, all but four tattooed lesions (61 of $65,93.8 \%$ ) were detected and removed by the surgeons (Fig. 2). One of the four undetected lesions was located deep in the spermatic cord. After follow-up US that revealed the remaining lesion, US-guided tattooing of the lesion was performed again, and the lesion was successfully removed by subsequent surgery. One of the other undetected lesions was located in the thigh, and two were located in the calf. The lesion in the thigh was removed by subsequent surgery after repeated US-guided tattooing; the lesions in the calf were removed with the guidance of intraoperative US. No relevant complications were noted in the medical records or radiology reports of the patients who underwent US-guided tattooing procedures. 


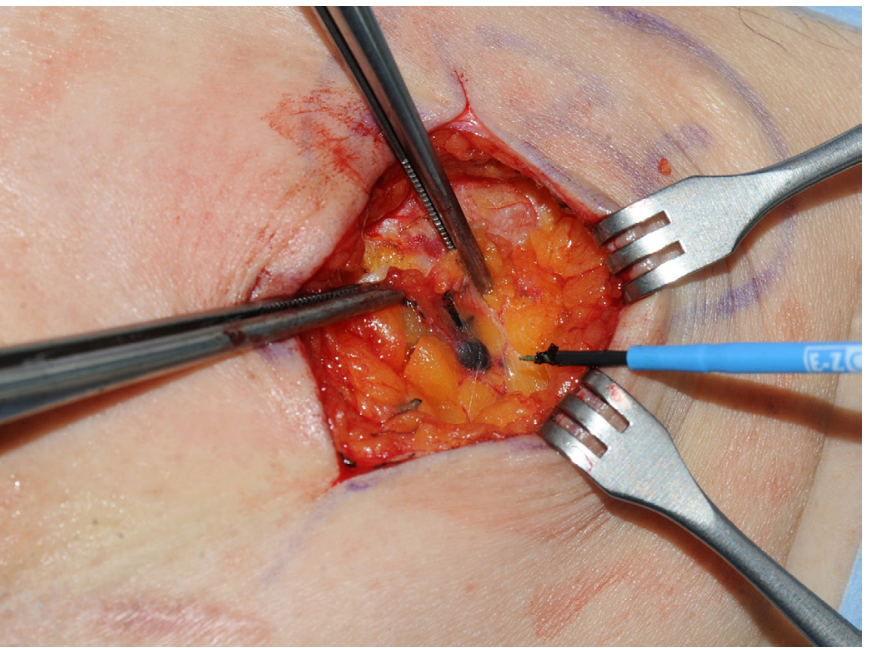

A

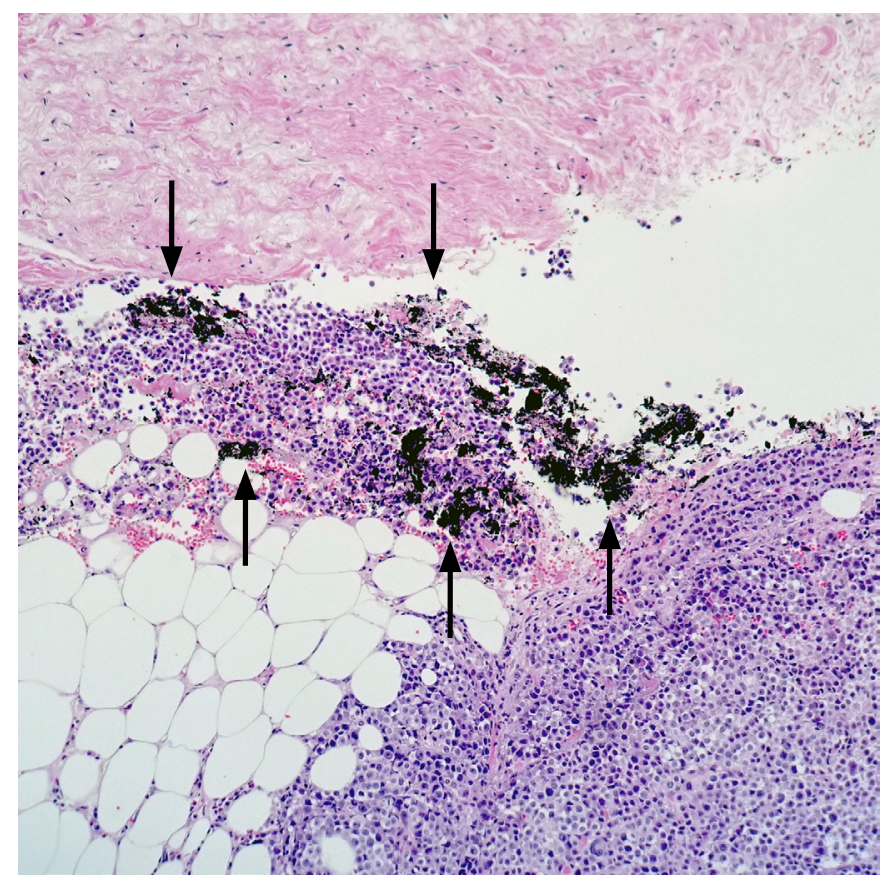

C

\section{Discussion}

The management of melanoma requires a multidisciplinary approach, but surgical removal still remains the mainstay of treatment for primary tumors with regional lymph node, in-transit, or distant metastasis and locoregional recurrent disease $[8,9,14,26,27]$. US has been widely used for surveillance of metastatic lesions and guidance for aspiration or biopsy in patients with melanoma, but its role in the localization of nonpalpable metastasis to aid in precise surgical removal has been scarcely reported [13]. We hypothesized that US could contribute to the surgical management of patients

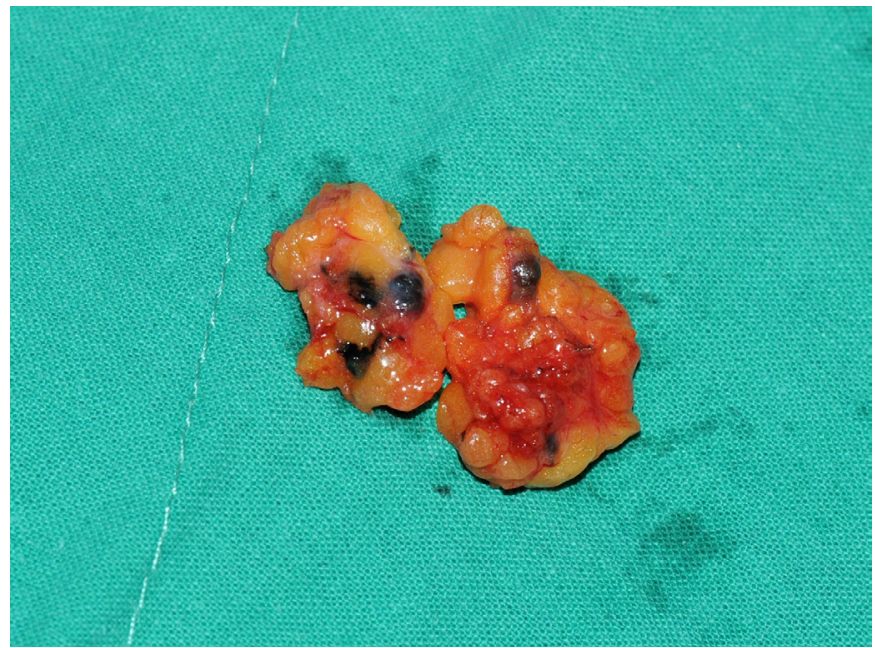

B

Fig. 2. A lymph node tattooed with charcoal suspension.

A. In the operative field, a lymph node tattooed with charcoal suspension can easily be identified as a dark nodular lesion. B. A resected specimen shows multiple charcoal-tattooed lymph nodes. C. A low-power-field (H\&E staining, $\times 100$ ) microscopic view shows tattoo pigment (arrows) along the periphery of the metastatic lesion.

with metastatic melanoma by guiding preoperative lesion localization with a charcoal injection.

Our results showed that US-guided tattooing localization using a charcoal suspension could effectively facilitate the subsequent surgical removal of nonpalpable metastatic melanoma. Most tattooed lesions ( 61 of $65,93.8 \%$ ) could be identified and removed intraoperatively. This result is comparable to the result of the USguided tattooing performed for metastatic lesions in breast and thyroid cancer $[20,23,28]$. Two of the four lesions that were unsuccessfully excised after initial localization could be removed after repeated tattooing localization, while the other two lesions 
were removed under intraoperative US guidance. The tattooing procedure enabled the localization and removal of relatively small lesions, with a mean size of $9.8 \mathrm{~mm}$, which is comparable to the size of the target lesions in previous reports on US-guided tattooing localization $[20,22]$. Some of the lesions were in proximity to major vascular structures, but no significant procedure-related complications were noted. According to a previous study on the USguided tattooing localization of metastatic cervical lymph nodes in thyroid cancer, lesions adherent to the major neck vessels, such as the common carotid artery and internal jugular vein, could be safely tattooed without any complications [23].

The preoperative localization of metastatic melanoma using a wire has been reported in a few studies $[16,18,19]$. Those studies have suggested that wire localization can be a useful procedure to facilitate the surgical removal of nonpalpable metastatic melanoma, yet the number of studied cases was small. Presurgical wire localization has been mainly studied in nonpalpable breast lesions $[29,30]$. Complications related to wire insertion in breast lesions, such as wire migration, wound infection, and bleeding have been reported [31-33]. Compared to the wire localization technique, tattooing localization has a number of advantages. Since the wire is inserted from outside the patient's body, it can cause discomfort and pain. In contrast, the tattooing procedure causes less discomfort in the patient after the procedure, which may allow tattooing of multiple lesions. Additionally, to prevent wire migration after its placement to localize the lesion, it is essential that surgical removal of the lesion is performed as soon as possible after the procedure is completed [34]. In contrast, previous studies on preoperative tattooing localization have reported that the charcoal suspension persists for months after its injection $[20,28,35]$. Although it would be desirable to have a short interval between tattooing localization and surgery, the stability of the charcoal suspension may reduce scheduling issues for surgery. The localization of metastatic melanoma with intralesional injections of radioactive seeds has also been reported, but in limited cases $[15,17]$. Further studies with larger cohorts are needed to compare the efficacy and safety of these procedures in patients with melanoma.

We could not find any relevant complications in the medical records or radiology reports of the patients we analyzed, even though there may have been unreported minor complications. Charcoal tattooing is not considered to be a significantly demanding procedure for patients and reported to be well tolerated without severe pain, even in the head and neck region, which has rich innervation and vulnerability to pain $[36,37]$. Charcoal itself is an innocuous substance that has been used to localize malignant lesions over the past decades [23]. To the best of our knowledge, no major complications, including toxicity, related to charcoal have not been reported in the setting of preoperative tattooing localization for malignancies $[20-25,37]$. Nonetheless, it would still be desirable to have larger-scale data to ensure the long-term safety of this procedure in patients with melanoma in future studies.

Five lesions were shown to have inconclusive histology or an inadequate tissue specimen after aspiration prior to tattooing. Although aspiration cytology offers excellent diagnostic accuracy in the diagnosis of metastatic melanoma [38], an accurate diagnosis can be hindered by inadequate quality of the acquired specimen, and in such cases, surgical excision is required for a definitive diagnosis. Moreover, when multiple suspicious lymph node metastases are detected on US, a cytologic evaluation cannot be conducted for all suspected lesions. In such cases, US-guided tattooing can be used to mark those suspected lesions in addition to the cytologically proven metastasis. We believe that US-guided tattooing localization may also play a role from a diagnostic perspective in aiding surgical excision to establish accurate assessment of metastatic lesions.

Our study has several limitations. First, even though this procedure has been accepted as safe for a number of malignancies, a longterm follow-up evaluation of its potential effects on recurrence (possibly related to the procedure) in patients with melanoma has not been performed. Nonetheless, we believe that the benefit of this procedure in aiding the intraoperative detection and removal of nonpalpable lesions overwhelms this potential risk. Second, the successful surgical removal rate was not compared with that achieved using other localization methods or without localization. Third, a person's level of experience performing the procedure may have a certain influence on the rate of successful localization. Finally, even though the amount of injected charcoal was extremely small, it was not recorded. Likewise, the exact amount of charcoal required to optimize visibility during surgery remains to be confirmed.

Therefore, US-guided tattooing localization using a charcoal suspension can be an effective method of facilitating visual localization of nonpalpable metastatic melanoma lesions. Further studies are warranted to evaluate the long-term benefits and potential complications of the procedure and to compare its effectiveness with that of other localization methods or no localization in patients with melanoma.

ORCID: Ji Hyun Lee: https://orcid.org/0000-0002-8582-5436; Hyun Su Kim: https://orcid.org/0000-0002-0179-9542; Young Cheol Yoon: https://orcid.org/00000002-7822-5344; Min Je Kim: https://orcid.org/0000-0003-3672-7052; Min Jae Cha: https://orcid.org/0000-0001-6358-8081; Jung-Han Kim: https://orcid.org/00000002-2265-5556

\section{Author Contributions}

Conceptualization: Kim HS. Data acquisition: Kim HS, Kim MJ. Data 
analysis or interpretation: Kim HS, Lee JH. Drafting of the manuscript: Kim HS, Lee JH, Cha MJ. Critical revision of the manuscript: Yoon YC, Kim JH. Approval of the final version of the manuscript: all authors.

\section{Conflict of Interest}

No potential conflict of interest relevant to this article was reported.

\section{References}

1. Garbe C, Peris K, Hauschild A, Saiag P, Middleton M, Bastholt L, et al. Diagnosis and treatment of melanoma. European consensusbased interdisciplinary guideline: update 2016. Eur J Cancer 2016;63:201-217.

2. Pflugfelder A, Kochs C, Blum A, Capellaro M, Czeschik C, Dettenborn T, et al. Malignant melanoma S3-guideline "diagnosis, therapy and follow-up of melanoma". J Dtsch Dermatol Ges 2013;11 Suppl 6:1-116.

3. Ghaferi $A A$, Wong $S L$, Johnson TM, Lowe $L$, Chang $A E$, Cimmino VM, et al. Prognostic significance of a positive nonsentinel lymph node in cutaneous melanoma. Ann Surg Oncol 2009;16:29782984.

4. Leiter U, Stadler R, Mauch C, Hohenberger W, Brockmeyer N, Berking $C$, et al. Complete lymph node dissection versus no dissection in patients with sentinel lymph node biopsy positive melanoma (DeCOG-SLT): a multicentre, randomised, phase 3 trial. Lancet Oncol 2016;17:757-767.

5. Grotz TE, Mansfield AS, Kottschade LA, Erickson LA, Otley CC, Markovic SN, et al. In-transit melanoma: an individualized approach. Oncology (Williston Park) 2011;25:1340-1348.

6. Hayes AJ, Clark MA, Harries M, Thomas JM. Management of intransit metastases from cutaneous malignant melanoma. Br J Surg 2004;91:673-682.

7. Perone JA, Farrow N, Tyler DS, Beasley GM. Contemporary approaches to in-transit melanoma. J Oncol Pract 2018;14:292300.

8. Testori A, Ribero S, Bataille V. Diagnosis and treatment of in-transit melanoma metastases. Eur J Surg Oncol 2017;43:544-560.

9. Leung AM, Hari DM, Morton DL. Surgery for distant melanoma metastasis. Cancer J 2012;18:176-184.

10. Bafounta ML, Beauchet $A$, Chagnon S, Saiag P. Ultrasonography or palpation for detection of melanoma nodal invasion: a metaanalysis. Lancet Oncol 2004;5:673-680.

11. Xing Y, Bronstein Y, Ross MI, Askew RL, Lee JE, Gershenwald JE, et al. Contemporary diagnostic imaging modalities for the staging and surveillance of melanoma patients: a meta-analysis. J Natl Cancer Inst 2011;103:129-142.

12. Voit CA, Gooskens SL, Siegel P, Schaefer G, Schoengen A, Rowert $J$, et al. Ultrasound-guided fine needle aspiration cytology as an addendum to sentinel lymph node biopsy can perfect the staging strategy in melanoma patients. Eur J Cancer 2014;50:2280-2288.

13. Schafer-Hesterberg G, Schoengen A, Sterry W, Voit C. Use of ultrasound to early identify, diagnose and localize metastases in melanoma patients. Expert Rev Anticancer Ther 2007;7:1707-1716.

14. Coit DG, Thompson JA, Algazi A, Andtbacka R, Bichakjian CK, Carson WE 3rd, et al. Melanoma, version 2.2016, NCCN clinical practice guidelines in oncology. J Natl Compr Canc Netw 2016; 14:450-473.

15. Fleming MD, Pockaj BA, Hansen AJ, Gray RJ, Patel MD. Radioactive seed localization for excision of non-palpable in-transit metastatic melanoma. Radiol Case Rep 2006;1:54-57.

16. Rodrigues LK, Habib FA, Wilson M, Turek L, Kerlan RK, Leong SP. Resection of metastatic melanoma following wire localization guided by computed tomography or ultrasound. Melanoma Res 1999;9:595-598.

17. Testori A, Rastrelli M, De Fiori E, Soteldo J, Della Vigna P, Trifiro G, et al. Radio-guided ultrasound lymph node localization: feasibility of a new technique for localizing and excising nonpalpable lymph nodes ultrasound suspicious for melanoma metastases. Melanoma Res 2010;20:197-202.

18. Voit C, Proebstle TM, Winter H, Kimmritz J, Kron M, Sterry W, et al. Presurgical ultrasound-guided anchor-wire marking of soft tissue metastases in stage III melanoma patients. Dermatol Surg 2001;27:129-132.

19. Shirley R, Uppal R, Vadodoria S, Powell B. Ultrasound-guided wire localisation for surgical excision of deep seated metastatic deposit of malignant melanoma. J Plast Reconstr Aesthet Surg 2009;62:e411-e412.

20. Kang TW, Shin JH, Han BK, Ko EY, Kang SS, Hahn SY, et al. Preoperative ultrasound-guided tattooing localization of recurrences after thyroidectomy: safety and effectiveness. Ann Surg Oncol 2009; 16:1655-1659.

21. Ko K, Han BK, Jang KM, Choe YH, Shin JH, Yang JH, et al. The value of ultrasound-guided tattooing localization of nonpalpable breast lesions. Korean J Radiol 2007:8:295-301.

22. Kwon H, Tae SY, Kim SJ, Jung KC, Kim JH, Lee KE, et al. Role of charcoal tattooing in localization of recurred papillary thyroid carcinoma: initial experiences. Ann Surg Treat Res 2015;88:140144.

23. Song CM, Park JS, Park W, Ji YB, Cho SH, Tae K. Feasibility of charcoal tattooing for localization of metastatic lymph nodes in robotic selective neck dissection for papillary thyroid carcinoma. Ann Surg Oncol 2015;22 Suppl 3:S669-S675.

24. Park S, Koo JS, Kim GM, Sohn J, Kim SI, Cho YU, et al. Feasibility of charcoal tattooing of cytology-proven metastatic axillary lymph node at diagnosis and sentinel lymph node biopsy after neoadjuvant chemotherapy in breast cancer patients. Cancer Res Treat 2018;50:801-812. 
25. Soprani F, De Vito A, Bondi F, Magliulo G, Rene SS, Cappi C, et al. Preoperative charcoal suspension tattoo for the detection of differentiated thyroid cancer recurrence. Mol Clin Oncol 2019;10:524-530.

26. Farley CR, Delman KA. Management of melanoma locoregional recurrence. In: Riker Al, ed. Melanoma. Cham: Springer, 2019;351359.

27. Ollila DW, Hsueh EC, Stern SL, Morton DL. Metastasectomy for recurrent stage IV melanoma. J Surg Oncol 1999;71:209-213.

28. Patel R, MacKerricher W, Tsai J, Choy N, Lipson J, Ikeda D, et al. Pretreatment tattoo marking of suspicious axillary lymph nodes: reliability and correlation with sentinel lymph node. Ann Surg Oncol 2019;26:2452-2458.

29. Homer MJ. Nonpalpable breast lesion localization using a curvedend retractable wire. Radiology 1985;157:259-260.

30. Homer MJ, Smith TJ, Safaii H. Prebiopsy needle localization: methods, problems, and expected results. Radiol Clin North Am 1992;30:139-153.

31. Kopans DB. Migration of breast biopsy localization wire. AJR Am J Roentgenol 1988;151:614-615.

32. Davis PS, Wechsler RJ, Feig SA, March DE. Migration of breast biopsy localization wire. AJR Am J Roentgenol 1988;150:787-788.

33. Ernst MF, Avenarius JK, Schuur KH, Roukema JA. Wire localization of non-palpable breast lesions: out of date? Breast 2002;11:408413.

34. Ahmed M, Rubio IT, Klaase JM, Douek M. Surgical treatment of nonpalpable primary invasive and in situ breast cancer. Nat Rev Clin Oncol 2015;12:645-663.

35. Mathieu MC, Bonhomme-Faivre L, Rouzier R, Seiller M, BarreauPouhaer $L$, Travagli JP. Tattooing breast cancers treated with neoadjuvant chemotherapy. Ann Surg Oncol 2007;14:2233-2238.

36. Tirelli G, Cova MA, Boscolo-Rizzo P, Da Mosto MC, Makuc E, Gardenal N. Charcoal suspension tattoo: a new technique for intraoperative detection of small tumors of the parotid gland. Ann Otol Rhinol Laryngol 2016;125:529-535.

37. Tirelli G, Cova MA, Zanconati F, Makuc E, Bonazza D, Tofanelli M, et al. Charcoal suspension tattoo: new tool for the localization of malignant laterocervical lymph nodes. Eur Arch Otorhinolaryngol 2016;273:3973-3978.

38. Hall BJ, Schmidt RL, Sharma RR, Layfield LJ. Fine-needle aspiration cytology for the diagnosis of metastatic melanoma: systematic review and meta-analysis. Am J Clin Pathol 2013;140:635-642. 